\title{
ASSOCIATIONS BETWEEN NECK MUSCULOSKELETAL COMPLAINTS AND WORK RELATED FACTORS AMONG PUBLIC SERVICE COMPUTER WORKERS IN KAUNAS
}

\section{GINTARÉ KALINIENE, RUTA USTINAVICIENE, LINA SKEMIENE, and VIDMANTAS JANUSKEVICIUS}

Lithuanian University of Health Sciences, Kaunas, Lithuania

Department of Environmental and Occupational Medicine of Medical Academy

\begin{abstract}
Objectives: Information technologies have been developing very rapidly, also in the case of occupational activities. Epidemiological studies have shown that employees, who work with computers, are more likely to complain of musculoskeletal disorders (MSD). The aim of this study was to evaluate associations between neck MSD and individual and work related factors. Materials and Methods: The investigation which consisted of two parts - a questionnaire study (using Nordic Musculoskeletal questionnaire and Copenhagen Psychosocial Questionnaire) and a direct observation (to evaluate ergonomic work environment using RULA method) was carried out in three randomly selected public sector companies of Kaunas. The study population consisted of 513 public service office workers. Results: The survey showed that neck MSDs were very common in the investigated population. The prevalence rate amounted to 65.7\%. According to our survey neck MSDs were significantly associated with older age, bigger work experience, high quantitative and cognitive job demands, working for longer than $2 \mathrm{~h}$ without taking a break as well as with higher ergonomic risk score. The fully adjusted model working for longer than $2 \mathrm{~h}$ without taking a break had the strongest associations with neck complaints. Conclusion: It was confirmed, that neck MSDs were significantly associated with individual factors as well as conditions of work, therefore, preventive actions against neck complaints should be oriented at psychosocial and ergonomic work environment as well as at individual factors.
\end{abstract}

Key words:

Computer work, The neck MDSs, Psychosocial factors, Ergonomics

\section{INTRODUCTION}

In recent decades development of information technologies has led to many changes in workers' professional practice. A computer has become indispensable in a number of fields. Recent EUROSTAT data shows that as much as $51 \%$ of European workers population is using computers in their work on a daily basis [1]. According to the Lithuanian Department of Statistics, the number of employees working with computers in various companies amounts to $31.4 \%$ [2].

Epidemiological studies have shown that employees, who work with computers, are more likely to complain of musculoskeletal disorders (MSDs) [3-5]. Scientific studies

The study is a part of an epidemiologic research „Ergonomics of computer work and its interface with the psychosocial work environment”, carried out in the Department of Environmental and Occupational Medicine at LUHS MA in 2010.

Received: October 23, 2012. Accepted: September 9, 2013.

Corresponding author: G. Kaliniene, Department of Environmental and Occupational Medicine of Medical Academy of Lithuanian University of Health Sciences, Eivenių g. 4-115 LT-50161 Kaunas, Lithuania (e-mail: gintare.kaliniene@1smuni.lt). 
also acknowledge that one of the most vulnerable areas of MSDs among the aforesaid employees is neck [6-9].

Working with a computer encompasses a range of various physical work environment factors as well as interaction between them, e.g. the interaction between the workplace, the devices and the speed of data entry or the interface between the work posture and the objects being watched (such as the screen, documents, etc.) as well as the content of work. That is why scientists admit that MSDs have a multifactorial etiology. According to the scientific data, there is a great relationship between individual factors, such as gender, age, history of previous injuries, body mass index (BMI) and MSDs [10-13]. Work environment has an undisputable impact on the development of MSDs [14]. It has been established that the increased risk of MSDs is related to the posture and movements during work [15-17].

As early as in the 1990s psychosocial risk factors started to be explored as notably significant to the etiology of MSDs development. In respect to MSDs, psychosocial factors operate jointly with ergonomic factors of work environment as well as individual qualities of an employee, creating such a response, which acts as a protective or increasing the risk of MSDs combination [18]. According to the scientific data, enormous workload, monotonous work, unclear assignments as well as insufficient social support are related to MSDs in different areas of the body [14]. In this study we explored associations between the musculoskeletal neck complaints and individual factors as well as factors of work environment among the employees, who work with computers.

\section{MATERIALS AND METHODS}

Data used in this study constitutes a part of the cross - sectional epidemiologic study 'Ergonomics of computer work and its interface with the psychosocial work environment', carried out in the Department of Environmental and Occupational Medicine at LUHS MA in 2010. Employees from three randomly selected public sector companies of Kaunas were invited to participate in the study. Data was collected using a questionnaire study and a method of direct observation, which was performed in order to evaluate associations between the neck complaints and the individual factors as well as work related factors among the employees who work with computers. 570 employees received the questionnaires and 513 employees agreed to participate in the study and filled in the questionnaire properly (response rate of $89.1 \%$ ).

\section{Instrument of a questionnaire study}

A three-part questionnaire was used to implement the questionnaire study. The first part comprised of questions that were designed to obtain individual data of the respondents (age, gender, computer experience, height, weight). The division into age categories was done for the purpose of a more convenient statistical analysis, the range of age was divided into four equal age groups (every decade), and just the last one covered two decades, because only $8.1 \%$ of the respondents were from the last decade. Computer work experience was categorized into three groups. The second part was intended to assess the 12-month prevalence of neck complaints. For this purpose the Nordic Musculoskeletal Questionnaire was used [19]. The third part was meant to evaluate the psychosocial work environment by the use of the standardized Copenhagen Psychosocial Questionnaire [20]. Eight scales of Copenhagen Psychosocial Questionnaire, each made up of a certain combination of questions, were used in the study. Every question had five possible answers (always, often, sometimes, rarely, never or correct, almost correct, somewhat correct, almost wrong, wrong). Answer options were inverted into the scoring system of 100 to 0 . Each rating scale corresponded to the average scale score, calculated for each respondent. Depending on the average scale score the respondents were divided into three groups, according to the boundaries of tertiles high, medium and low levels of the observed phenomena. 
The main characteristics of the scales (name of the scale, number of questions in the scale, the internal reliability of the scale, assessed Cronbach's $\alpha$ ) are shown in Table 1. Reliability was good at $\alpha>0.7$.

Table 1. Main scales characteristics of Copenhagen Psychosocial Questionnaire

\begin{tabular}{lcc}
\hline \multicolumn{1}{c}{ Scale } & Questions (n) & Cronbah's $\alpha$ \\
\hline Quantitative demands & 8 & 0.72 \\
Cognitive demands & 9 & 0.81 \\
Emotional demands & 4 & 0.80 \\
Sensory demands & 6 & 0.69 \\
Influence at work & 10 & 0.58 \\
Possibilities for development & 7 & 0.77 \\
Social support & 4 & 0.84 \\
Job satisfaction & 8 & 0.83 \\
\hline
\end{tabular}

\section{Instrument of ergonomic investigation}

During the study the RULA (Rapid Upper Limb Assessment) method, adapted to the conditions of working with a computer [21], was used to evaluate the posture of different areas of the body at work as well as the risk of movement. The higher the score, the higher the risk for certain musculoskeletal area. The "Ergonomic evaluation of an employee" sheets were filled in following the method of the aforementioned instrument. The scores of assessments of the neck posture and movements' risk were used in this study. Estimation of the neck posture and movements: neutral (straight) position of the neck - 1 point, neck inclination forward by $20^{\circ}-2$ points, $>20^{\circ}-3$ points, if the neck was thrown back at any angle -4 points. If the neck was being constantly twirled or bent from side to side, every movement counted as one additional point. The maximum number of points assessing the risk to the neck area was 6 points.

Statistical data analysis was performed using an SPSS software package (version 15.0). Hypotheses about the equality between the average values of two quantitative variables and two percentages variables were examined by the use of the Mann-Whitney $\mathrm{U}$ test and $\mathrm{z}$ tests respectively. Values of $p \leq 0.05$ were considered statistically significant, while those of $p \leq 0.001$ highly significant. In order to determine whether the selected individual as well as work related factors were associated with the complaints of neck, logistic regression analysis (multivariate) was applied. Two models were estimated: in Model I, all independent variables were separately adjusted for age. Model II was adjusted for all the independent variables simultaneously. The results of the analysis are presented as odds ratio (OR) and $95 \%$ of its confidence interval (CI). Parameters that displayed significant ORs $>1$ were interpreted as increasing probability of experiencing the MSDs as compared to the reference group $(\mathrm{OR}=1)$.

\section{RESULTS}

According to the survey, 65.7\% ( $\mathrm{N}=337)$ of all the participating respondents, who were working with computers ( $\mathrm{N}=513)$, had musculoskeletal complaints of the neck region. The prevalence of these complaints was analyzed with respect to individual factors as well as work environment factors (Table 2). Distribution of the investigated complaints, considering individual factors, showed that older employees, as well as those, with greater computer work experience reported MSDs in the neck area more often. Compared to the youngest (23-29 years of age) group of employees the 40-49 years of age respondents had 2.37 times (95\% CI: 1.25-4.49) greater probability of experiencing MSDs in the neck area, whereas 50-70 year olds - 1.93 times (95\% CI: 1.09-3.63) (Table 3). Employees with the largest experience of working with computers (16-36 years) had a 2.42 times (95\% CI: $1.40-4.20)$ greater probability of complaints as well as employees with 6-15 years of experience -2.25 times (95\% CI: 1.443.52 ) in comparison with the employees, who had been working with computers for the shortest period of time. 
Table 2. Prevalence of the neck musculoskeletal disorders (MSD) with respect to individual and work related factors

\begin{tabular}{|c|c|c|c|}
\hline \multirow{2}{*}{ Parameters } & \multicolumn{3}{|c|}{$\begin{array}{c}\text { Neck MSD } \\
\mathrm{n}(\%)\end{array}$} \\
\hline & $\begin{array}{c}\text { yes } \\
(\mathrm{N}=337)\end{array}$ & $\begin{array}{c}\text { no } \\
(\mathrm{N}=176)\end{array}$ & $\begin{array}{c}\text { total } \\
(\mathrm{N}=513)\end{array}$ \\
\hline \multicolumn{4}{|l|}{ Age (years) } \\
\hline $23-29$ & $28(50.9)$ & $27(49.1)$ & $55(100)$ \\
\hline $30-39$ & $56(61.5)$ & $35(38.5)$ & $91(100)$ \\
\hline $40-49$ & $106(71.1)^{\mathrm{a}}$ & $43(28.9)$ & $149(100)$ \\
\hline $50-70$ & $147(67.4)^{\mathrm{a}}$ & $71(32.6)$ & $218(100)$ \\
\hline \multicolumn{4}{|c|}{ Computer work experience (years) } \\
\hline $1-5$ & $58(50.4)$ & $57(49.6)$ & $115(100)$ \\
\hline $6-15$ & $200(69.7)^{b}$ & $87(30.3)$ & $287(100)$ \\
\hline $16-36$ & $79(71.2)^{\mathrm{b}}$ & $32(28.8)$ & $111(100)$ \\
\hline \multicolumn{4}{|l|}{ Body Mass Index } \\
\hline$<18.5$ & $10(52.6)$ & $9(47.4)$ & $18(100)$ \\
\hline $18.6-24.9$ & $164(64.8)$ & $89(35.2)$ & $253(100)$ \\
\hline$>25$ & $157(67.1)$ & $77(32.9)$ & $234(100)$ \\
\hline \multicolumn{4}{|l|}{ Quantitative demands } \\
\hline low & $120(57.7)$ & $88(42.3)$ & $208(100)$ \\
\hline average & $97(67.8)^{*}$ & $46(32.2)$ & $143(100)$ \\
\hline high & $120(74.1)^{* *}$ & $42(25.9)$ & $162(100)$ \\
\hline \multicolumn{4}{|l|}{ Cognitive demands } \\
\hline low & $76(53.9)$ & $65(46.1)$ & $141(100)$ \\
\hline average & $135(70.7)^{* *}$ & $56(29.3)$ & $191(100)$ \\
\hline high & $126(69.9)^{*}$ & $55(30.4)$ & $181(100)$ \\
\hline \multicolumn{4}{|l|}{ Emotional demands } \\
\hline low & $122(63.5)$ & $70(36.5)$ & $192(100)$ \\
\hline average & $93(68.9)$ & $42(31.1)$ & $135(100)$ \\
\hline high & $122(65.6)$ & $64(34.4)$ & $186(100)$ \\
\hline \multicolumn{4}{|l|}{ Sensory demands } \\
\hline low & $119(63.3)$ & $69(36.7)$ & $188(100)$ \\
\hline average & $45(65.2)$ & $24(34.8)$ & $69(100)$ \\
\hline high & $173(67.6)$ & $83(32.4)$ & $256(100)$ \\
\hline \multicolumn{4}{|l|}{ Influence at work } \\
\hline low & $145(68.1)$ & $68(31.9)$ & $213(100)$ \\
\hline average & $83(62.4)$ & $50(37.6)$ & $133(100)$ \\
\hline high & $109(65.3)$ & $58(34.7)$ & $167(100)$ \\
\hline
\end{tabular}


Table 2. Prevalence of the neck musculoskeletal disorders (MSD) with respect to individual and work related factors - cont.

\begin{tabular}{|c|c|c|c|}
\hline \multirow{2}{*}{ Parameters } & \multicolumn{3}{|c|}{$\begin{array}{c}\text { Neck MSD } \\
\mathrm{n}(\%)\end{array}$} \\
\hline & $\begin{array}{c}\text { yes } \\
(\mathrm{N}=337)\end{array}$ & $\begin{array}{c}\text { no } \\
(\mathrm{N}=176)\end{array}$ & $\begin{array}{c}\text { total } \\
(\mathrm{N}=513)\end{array}$ \\
\hline \multicolumn{4}{|l|}{ Possibilities for development } \\
\hline low & $78(57.4)^{*}$ & $58(42.6)$ & $136(100)$ \\
\hline average & $136(70.1)$ & $58(29.9)$ & $194(100)$ \\
\hline high & $123(67.2)$ & $60(32.8)$ & $183(100)$ \\
\hline \multicolumn{4}{|l|}{ Social support } \\
\hline weak & $110(60.1)$ & $73(39.9)$ & $183(100)$ \\
\hline average & $99(71.7)^{*}$ & $39(28.3)$ & $138(100)$ \\
\hline strong & $128(66.7)$ & $64(33.3)$ & $192(100)$ \\
\hline \multicolumn{4}{|l|}{ Job satisfaction } \\
\hline low & $104(62.7)$ & $62(37.3)$ & $166(100)$ \\
\hline average & $195(68.4)$ & $90(31.6)$ & $285(100)$ \\
\hline high & $38(61.3)$ & $24(38.7)$ & $62(100)$ \\
\hline \multicolumn{4}{|c|}{ Time duration of computer work (h/day) } \\
\hline$<4$ & $10(50.0)$ & $10(50.0)$ & $20(100)$ \\
\hline $4-6$ & $60(68.2)$ & $28(31.8)$ & $88(100)$ \\
\hline$>6$ & $267(65.9)$ & $138(34.1)$ & $405(100)$ \\
\hline \multicolumn{4}{|l|}{ Taking break every $2 \mathrm{~h}$} \\
\hline yes & $35(50.7)$ & $34(49.3)$ & $69(100)$ \\
\hline no & $302(68.0)^{\mathrm{c}}$ & $142(32.0)$ & $444(100)$ \\
\hline
\end{tabular}

$\mathrm{z}$ test:

${ }^{\mathrm{a}} \mathrm{p}<0.05$ - comparing with the youngest group; ${ }^{\mathrm{b}} \mathrm{p}<0.001$ - comparing with the smallest work experience group;

${ }^{c} \mathrm{p}<0.001$ - comparing with taking break every $2 \mathrm{~h}$;

$* \mathrm{p}<0.05 ; * \mathrm{*}<0.001$ - comparing with, working in a positive work environment with respect to current psychosocial factor.

Table 3. Logistic regression models for the neck musculoskeletal disorders (MSDs) as a dependant variable

\begin{tabular}{lcccc}
\hline \multirow{2}{*}{ Parameters } & \multicolumn{2}{c}{ I model* $^{*}$} & \multicolumn{2}{c}{ II model** } \\
\cline { 2 - 5 } & OR & $95 \%$ CI & OR & $95 \%$ CI \\
\hline Age (years) & & & & \\
$23-29$ & 1.00 & & 1.00 & \\
$30-39$ & 1.53 & $0.78-3.03$ & 1.03 & $0.44-2.37$ \\
$40-49$ & 2.37 & $1.25-4.49$ & 1.11 & $0.46-2.67$ \\
$50-70$ & 1.93 & $1.09-3.63$ & 1.02 & $0.40-2.28$ \\
Computer work experience (years) & & & & \\
1-5 & 1.00 & & 1.00 & \\
6-15 & 2.25 & $1.44-3.52$ & 2.16 & $1.17-3.98$ \\
$16-36$ & 2.42 & $1.40-4.20$ & 2.19 & $1.06-4.54$ \\
\hline
\end{tabular}


Table 3. Logistic regression models for the neck musculoskeletal disorders (MSDs) as a dependant variable - cont.

\begin{tabular}{|c|c|c|c|c|}
\hline \multirow{2}{*}{ Parameters } & \multicolumn{2}{|c|}{ I model ${ }^{*}$} & \multicolumn{2}{|c|}{ II model** } \\
\hline & OR & $95 \% \mathrm{CI}$ & OR & $95 \% \mathrm{CI}$ \\
\hline \multicolumn{5}{|c|}{ Body Mass Index } \\
\hline$<18.5$ & 1.00 & & 1.00 & \\
\hline $18.6-24.9$ & 1.65 & $0.65-4.23$ & 1.02 & $0.32-2,86$ \\
\hline$>25$ & 1.83 & $0.71-4.70$ & 1.01 & $0.32-3.08$ \\
\hline \multicolumn{5}{|c|}{ Quantitative demands } \\
\hline low & 1.00 & & 1.00 & \\
\hline average & 1.84 & $1.05-2.41$ & 1.15 & $0.70-1.89$ \\
\hline high & 2.09 & $1.34-3.27$ & 1.67 & $1.01-2.79$ \\
\hline \multicolumn{5}{|c|}{ Cognitive demands } \\
\hline low & 1.00 & & 1.00 & \\
\hline average & 2.06 & $1.03-3.24$ & 1.69 & $1.05-2.84$ \\
\hline high & 1.95 & $1.23-3.09$ & 1.52 & $0.85-2.71$ \\
\hline \multicolumn{5}{|c|}{ Emotional demands } \\
\hline low & 1.00 & & 1.00 & \\
\hline average & 1.27 & $0.79-2.02$ & 1.10 & $0.69-1.87$ \\
\hline high & 1.09 & $0.71-1.66$ & 1.01 & $0.52-1.39$ \\
\hline \multicolumn{5}{|c|}{ Sensory demands } \\
\hline low & 1.00 & & 1.00 & \\
\hline average & 1.08 & $0.61-1.93$ & 1.02 & $0.50-1.81$ \\
\hline high & 1.20 & $0.81-1.79$ & 1.20 & $0.70-1.77$ \\
\hline \multicolumn{5}{|c|}{ Influence at work } \\
\hline low & 1.13 & $0.73-1.74$ & 1.31 & $0.53-1.49$ \\
\hline average & 1.09 & $0.65-1.41$ & 1.05 & $0.80-2.15$ \\
\hline high & 1.00 & & 1.00 & \\
\hline \multicolumn{5}{|c|}{ Possibilities for development } \\
\hline low & 1.14 & $0.74-1.76$ & 1.23 & $0.75-2.02$ \\
\hline average & 1.07 & $0.41-1.03$ & 1.03 & $0.53-1.74$ \\
\hline high & 1.00 & & 1.00 & \\
\hline \multicolumn{5}{|c|}{ Social support } \\
\hline weak & 1.26 & $0.78-2.04$ & 1.29 & $0.77-2.20$ \\
\hline average & 1.14 & $0.49-1.14$ & 1.04 & $0.42-1.18$ \\
\hline strong & 1.00 & & 1.00 & \\
\hline \multicolumn{5}{|c|}{ Job satisfaction } \\
\hline low & 1.36 & $0.77-2.41$ & 1.28 & $0.61-2.69$ \\
\hline average & 1.05 & $0.58-1.93$ & 1.44 & $0.75-2.77$ \\
\hline high & 1.00 & & 1.00 & \\
\hline
\end{tabular}


Table 3. Logistic regression models for the neck musculoskeletal disorders (MSDs) as a dependant variable - cont.

\begin{tabular}{lcccc}
\hline \multirow{2}{*}{ Parameters } & \multicolumn{2}{c}{ I model* $^{*}$} & \multicolumn{2}{c}{ II model** } \\
\cline { 2 - 5 } & OR & $95 \%$ CI & OR & $95 \%$ CI \\
\hline Time duration of computer work (h/day) & & & & \\
$\quad<4$ & 1.00 & & 1.00 & \\
$\quad 4-6$ & 2.14 & $0.80-5.73$ & 1.78 & $0.60-5.27$ \\
$>6$ & 1.93 & $0.78-4.76$ & 1.46 & $0.52-4.07$ \\
Taking break every 2 $\mathrm{n}$ & & & & \\
$\quad$ yes & 1.00 & & 1.00 & \\
$\quad$ no & 2.06 & $1.23-3.44$ & 1.59 & $1.05-2.89$ \\
Neck posture and movements evaluation & 1.22 & $1.15-1.51$ & 1.19 & $0.95-2.89$ \\
\hline
\end{tabular}

OR - odds ratio; $\mathrm{CI}$ - confidence interval.

* Adjusted for age.

** Adjusted for age, work experience, BMI, quantitative demands, cognitive demands, emotional demands, Sensory demands, influence at work, possibilities for development, social support, job satisfaction, time duration of computer work taking break every $2 \mathrm{~h}$, neck posture and movements evaluation.

While determining the relationship between the psychosocial work environment factors and MSDs in the neck region we discovered that the complaints were significantly more frequent in the group of employees who had high or average quantitative and cognitive demands at work (Table 2). Having compared the group of the respondents who had low quantitative demands, to the group of employees who encountered high and average quantitative demands, the latter two groups appeared to have greater probability of experiencing neck complaints by 2.09 times (95\% CI: $1.34-3.27$ ) and 1.84 times (95\% CI: $1.05-3.27$ ) respectively. High and average cognitive work demands in comparison with the low ones also increased the probability of neck complaints; the odds ratio was 2.09 (95\% CI: $1.23-$ 3.09 ) and 2.6 (95\% CI: 1.03-3.24) respectively. Complaints of the neck region were similarly distributed in different groups of emotional and sensual level of work demands no significant associations had been established. Paradoxically, the analysis of the distribution of the complaints has shown that the group of the respondents who had low possibilities for development at work also, significantly more rarely had the neck complaints in comparison with those, who had high possibilities for development. However, the results of logistic regression analysis did not show any significant associations between the aforementioned factors. Distribution of the complaints with reference to the level of social support showed, that the employees who were attributed to the average level of social support had complained more often than the group of strong social support respondents; the calculated OR with respect to this factor was not significant.

Analysis of the distribution of neck complaints also assessed the relationship between complaints and duration of time spent working with a computer as well as short breaks during work. It turned out, that the latter were highly significant - the complaint rate was significantly higher in the group that did not have any breaks; the calculated OR was 2.06 (95\% CI: 1.23-3.44). Time of work with a computer was not significant with respect to the complaints - the frequency of the complaints did not differ significantly between the groups in spite of the length of time spent on working with a computer.

Ergonomic evaluation of the posture and movements of the neck area showed that the average risk score among the studied population of workers was 2.49 ( $\mathrm{SD} \pm 0.86$ ). It has been established that the aforementioned score 
was significantly different in the groups of employees that had and did not have MSDs in the neck area ( $U=26877.0, p=0.053)$. The logistic regression analysis showed that the increase of the risk score by one unit increased the probability of complaints by 1.22 times (95\% CI: 1.15-1.51).

We performed a multivariate logistic regression analysis with the intention to explore the relationship between the neck complains and individual factors as well as work related factors further, all variables were added to the model by the use of the stepwise method ("enter"). To the best of the model data, presented in Table 3, MSDs in the neck area were significantly associated with greater work experience, high quantitative and average cognitive work requirements, and working with a computer longer than $2 \mathrm{~h}$ without taking a break. The strongest relationship was found between the neck complaints and the length of experience working with a computer.

\section{DISCUSSION}

This cross-sectional study is probably the only epidemiological research, which has been carried out in recent years in Lithuania and which intended to examine MSDs in the population of those working with computers. To the best of our knowledge, the last study, which was a complex investigation of a computerized workplace environment, was performed in 1999 in Lithuania [22]. Despite the fact that the level of computerization has increased rapidly, the occurrence of the musculoskeletal complaints in the neck region $(65.38 \%)$ that was established by the aforementioned study is very similar to the data obtained in our study $(65.7 \%)$, which is pretty high. In other countries of the world the complaints mentioned above among the population of computer workers ranged from $70 \%$ to $45 \%$, according to the data of various scientific studies $[4,7,11,23]$. It is also noteworthy, that in our population of the studied computer workers neck complaints were the most frequent MSD in comparison with other musculoskeletal areas - the prevalence of shoulder complaints amounted to $50.5 \%$, elbow $-20 \%$, writs $-26 \%$, upper back $-44.5 \%$ and low back $-56.1 \%$.

Having explored the relationship between neck complaints and the risk factors, we have approved a multifactorial etiology of MSDs development [18]. As far as individual factors are concerned, the risk of neck complaints increased with age and a larger experience of work with a computer. The relationship between age and the neck area MSDs was also confirmed by a great Belgian study, which showed that the complaints were statistically more prevalent in the group of elderly employees [7], Törnqvistet et al. having analyzed the cohort of computer workers for 10 years, observed that with regard to the complaints of the neck area, the most vulnerable group was that of middle-aged (36-50 years old) employees [24]. Due to the unequal division of the respondents into age groups and because of the differences in research design it would not be purposeful to compare the studies, however, it is important to denote that in our study the middle-aged (4049 years old) respondents also had the highest probability $(\mathrm{OR}=2.37$; 95\% CI: $1.25-4.49)$ of experiencing MSDs in the neck area. One could assume that the respondents of this particular age group had the largest experience of work with computers, which is exactly what our study has confirmed - the respondents with the largest experience of work with a computer had higher probability of the neck complaints. However, other researchers that had studied the relationship between this aspect and the complaints, did not establish any significant associations [9,25]. Many cross-sectional $[7,9,25]$ as well as follow up epidemiologic $[24,26,27]$ studies acknowledge the relationship between the gender and MSDs of neck. According to their data, women are more vulnerable with regard to these complaints and they have 1.8 to 3.07 times higher probability of experiencing MSDs in the neck in comparison with men. Our study did not confirm these results, because 
women are predominant in the population of Lithuanian public office workers, which resulted in $94.7 \%$ of the study participants being women, and only 5.3\% - men. For this reason the comparison of genders is insignificant.

According to our research data, BMI was not a significant factor for neck complaints, though prevalence of complaints was noticeably higher in the group of respondents with a larger BMI. Only few studies examine the relationship between the aforementioned factor and neck and shoulder area complaints. This factor is more frequently investigated as a factor predisposing to MSDs of upper and lower back. A large research, performed by German scientists, also found BMI to be irrelevant with respect to neck complaints in the population of employees working with computers [25].

Not only did our study show associations between individual factors and MSDs of the neck area, but also their associations with work related factors. Computerization and development of various technologies are closely related to constantly increasing job demands. Scientists admit that computerization has negative consequences for workers, which are associated with the increasing workload, intensive work as well as rising expectations of an employer [29,30]. These are considerable quantitative and cognitive demands at work that, according to our study, increased the probability of neck complaints. It should be mentioned that high job demands are often combined with quantitative, cognitive, emotional and sensory workload, and could be regarded as work pressure (which usually includes not only job demands, but also relationships with the employer and co-workers), complicated work tasks, work overload, physical/mental fatigue, and lack of staff. Canie et al. indicate in their study that high job demands, which are rated in three different categories - i.e. mental fatigue, lack of staff and being tired after a break - increased the probability of neck complaints [7], Ranasinghe et al. defined the aforementioned aspect as work overload, and also identified it as significant with respect to the complaints in the neck area. Törnqvist et al. confirm in their study, that high job demands combined with low decision latitude increase the risk of complaints of the neck more than twice [24]. Our study did not determine any relationships between the complaints and the level of influence at work as well as other psychosocial dimensions of possibilities for development at work, social support and a job satisfaction.

According to our research data, employees that spent more time working with a computer during a day, were not characterized as these who are more likely to experience neck MSDs; and this was confirmed by other authors' research [4,24]. However, it is worth mentioning that according to our research data, the absence of short breaks every $2 \mathrm{~h}$ significantly increased the risk of neck complaints.

When assessing the risk of complaints of MSDs comprehensively it is important to take into account ergonomics of working with a computer. Many studies that explore this aspect also assess ergonomics of the workstation (position of a computer device, chair, desk and their ability to adapt to the employee). Due to the fact that not only inadequacy of the workstation can determine the worker's posture and movements, we also assessed the ergonomics of computer work by the use of the RULA method, which evaluates the risk of an employee's posture and movements for certain areas of the body. The results have shown that the raised RULA risk score in the neck area significantly increased the probability of complaints in this area. We did not manage to find any studies that have assessed ergonomic risk by the use of the aforementioned method, however, epidemiological studies confirm, that improper working posture [9] as well as throwing back of the neck [27] increased the risk of such complaints.

Often both, psychosocial and other work environment related risks, were comprehensively assessed by an increased stress at work. Stress itself is a consequence and expression of negative factors, however, most studies, investigating 
MSDs, regard it as the risk factor. Some of them even confirm the associations between MSDs in the neck area and work related stress [11,27,31]. This assessment once more confirms the fact that MSDs have a multifactorial etiology. In the case of our study, applying the model of multivariable logistic regression, showed that both, individual as well as work environment factors, were significant to the neck area MSDs.

\section{Limitations}

The common limitation of a cross-sectional study is the possibility to analyze only the associations (correlations) between health complaints and risk factors, whereas causal relationship cannot be determined. Due to the fact that the presented study has demonstrated a high prevalence of neck MSDs, further follow up studies are required to evaluate the influence of work environment on the musculoskeletal system of computer workers.

\section{CONCLUSION}

Basing on the results of our study in the population of employees working with computers, the prevalence rate of neck MSDs was very high $-65.7 \%$. It is important that prevention programs would take into account all work related risk factors - ergonomic as well as psychosocial ones, in order to reduce the frequency of neck complaints. Particular attention should be paid to the work organization ensuring possibility of adequate work breaks every $2 \mathrm{~h}$. Also work environment should be properly adapted to the employees' individual work opportunities.

\section{REFERENCES}

1. Demunter Ch, E-skills measurement Working Party on Indicators for the Information Society, OECD, 2006 May 3-4, Paris. Eurostat [cited 2012 Sept 5]. Available from: http:// www.oecd.org/sti/ieconomy/36988541.pdf.
2. Lithuanian Department of Statistics. Statistical data of information technologies. 2012 [cited 2012 Sept 5]. Available from: http://www.stat.gov.lt/uploads/docs/Inf_zin_vis_pletr_ statist_rodikliai_091130.doc.

3. Cook C, Limerick B R, Chang S. The prevalence of neck and upper extremity musculoskeletal symptoms in computer mouse users. Int J Ind Ergon. 2000;26:347-56.

4. Sillanpää J, Huikko S, Nyberg M, Kivi P, Laippala P, Uitti P. Effect of work with visual display units on musculoskeletal disorders in the office environment. Occup Med. 2003;53: 443-51, http://dx.doi.org/10.1093/occmed/kqg120.

5. Jensen C. Development of neck and hand-wrist symptoms in relation to duration of computer use at work. Scand J Work Environ Health. 2003;29(3):197-205, http://dx.doi.org/10.5271/sjweh.722.

6. Jensen C, Finsen L, Sogaard K, Christensen H. Musculoskeletal symptoms and duration of computer and mouse use. Int J Ind Ergon. 2002;30(4-5):265-75, http://dx.doi. org/10.1016/S0169-8141(02)00130-0.

7. Canie B, Danneels L, Tiggelen D, De Loose V, Cambier D. Individual and work related risk factotors for neck pain among office workers: A cross sectional study. Eur Spine J. 2007;6:679-86.

8. Eltayeb S, Staal BJ, Kennes J, Lamberts P, Bie R. Prevalence of complains of arm, neck and shoulder among computer office workers and psychometric evaluation of a risk factor questionnaire. BMC Musculoskelet Disord. 2007;8:68, http://dx.doi.org/10.1186/1471-2474-8-68.

9. Ranasinghe P, Perera YS, Lamabadusuriya DA, Kulatunga S, Jayawardana N, Rajapakse S, et al. Work related complaints of neck, shoulder and arm among computer office workers: A cross sectional evaluation of prevalence and risk factors in a developing country. Environ Health. 2011;10:70, http:// dx.doi.org/10.1186/1476-069X-10-70.

10. Ekman A, Andersson A, Hagberg M, Hjelm EW. Gender differences in musculoskeletal health of computer and mouse users in the Swedish workforce. Occup Med (Lond.) 2000;50: 608-13, http://dx.doi.org/10.1093/occmed/50.8.608. 
11. Cook C, Limerick BR, Chang S. The prevalence of neck and upper extremity musculoskeletal symptoms in computer mouse users. Int J Ind Ergon. 2000;26:347-56, http://dx.doi. org/10.1016/S0169-8141(00)00010-X.

12. Spyropoulos P, Papathanasiou G, Georgoudis G, Chronopoulos E, Koutis H, Koumoutsou F. Prevalence of low back pain in Greek public office workers. Pain Physician. 2007;10:651-60.

13. Gerr F, Marcus M, Ensor C, Kleinbaum D, Cohen S, Edwards A, et al. A prospective study of computer users: study design and incidence of musculoskeletal symptoms and disorders. Am J Ind Med. 2002;41:221-35, http://dx.doi. org/10.1002/ajim.10066.

14. Bruce P, Bernard MD. Musculoskeletal disorders and workplace factors - A critical review of epidemiologic evidence for work-related musculoskeletal disorders of the neck, upper extremity, and low back.Cincinnati, Ohio: U.S. National Institute for Occupational Safety and Health; 1996 [cited 2012 Aug 6]. Available from: http://faculty.ksu.edu. sa/alsaleh/WMSDFILES/WMSD\%20Workplace\%20factors.pdf.

15. Ariens GA, Bongers PM, Douwes M, Miedema M, Hoogendoorn W, van der Wal G, et al. Are neck flexion, neck rotation, and sitting at work risk factors for neck pain? Results of a prospective cohort study. Occup Environ Med. 2001;58:200-7, http://dx.doi.org/10.1136/oem.58.3.200.

16. Punnet L, Bergqvist U. Visual display unit work and upper extremity musculoskeletal disorders - A review of epidemiological findings. Stockholm: National Institute for Working Life - ergonomic expert. Committee Document No 1; 1997.

17. Tittiranonda P, Burastero S, Rempel D. Risk factors for musculoskeletal disorders among computer users. Occup Med. 1999;14:17-38.

18. Feuerstein M, Nicholas RA, Huang GD, Haufler AJ, Pransky G, Robertson M. Work style: Development of a measure of response to work in those with upper extremity pain. J Occup Rehabil. 2005;15(2):87-104, http://dx.doi.org/10.1007/s10926005-3420-0.
19. Kuorinka I, Jonsson B, Kilbom A, Vinterberg H, BieringSorensen F, Andersson G. et al. Standardized Nordic questionnaires for the analysis of musculoskeletal symptoms. Appl Ergon. 1987;18:233-7, http://dx.doi.org/10.1016/00036870(87)90010-X.

20. Kristensen TS. A new tool for assessing psychosocial factors at work: the Copenhagen Psychosocial Questionnaire. TUTB Newsl. 2002;19-20:45-4.

21. Lueder R. A Proposed RULA for Computer Users. San Fransisco: UC Berkeley Center for Occupational \& Environmental Health Continuing Education Program; 1996.

22. Telksnienė R. Psychophysiological changes at VDT work. Medicina (Kaunas.) 2000;36:311-8.

23. Jensen C, Borg V, Finsen L, Hansen K, Kristensen J, Christensen H. Job demands, muscle activity and musculoskeletal symptoms in relation to work with the computer mouse. Scand J Work Environ Health. 1998;24(5):418-24, http:// dx.doi.org/10.5271/sjweh.364.

24. Tornqvist EW, Hagberg M, Hagman M, Risberg EH, Toomingas A. The influence of working conditions and individual factors on the incidence of neck and upper limb symptoms among professional computer users. Int Arch Occup Environ Health. 2009;82:689-702, http://dx.doi.org/10.1007/s00420009-0396-7.

25. Klussmann A, Gebhardt H, Liebers F, Rieger MA. Musculoskeletal symptoms of the upper extremities and the neck: A cross sectional study on prevalence and symptompredicting factors at visual display terminal (VDT) workstations. BMC Musculoskelet Disord. 2008;9:96, http://dx.doi. org/10.1186/1471-2474-9-96.

26. Korhonen T, Ketola R, Toivonen R, Luukkonen R, Häkkänen M, Viikari-Juntura E. Work related and individual predictors for incident neck pain among office employees working with video display units. Occup Environ Med. 2003;60:475-82, http://dx.doi.org/10.1136/oem.60.7.475.

27. Hush MJ, Michaleff Z, Maher GC, Refshauge K. Individual, physical and psychological risk factors for neck pain in Australian office workers: A 1-year longitudinal study. 
Eur Spine J. 2009;18:1532-40, http://dx.doi.org/10.1007/ s00586-009-1011-z.

28. Eltayeb S, Staal JB, Hassan A, Bie AR. Work related risk factors for neck, shoulder and arms complaints: A cohort study among Dutch computer office workers. J Occup Rehabil. 2009;19: 315-22, http://dx.doi.org/10.1007/s10926-009-9196-x.

29. Carayon P, Smith MJ. Work organization and ergonomics. Appl Ergon. 2000;31(6):649-62, http://dx.doi.org/10.1016/ S0003-6870(00)00040-5.
30. Amick BC, Smith MJ. Stress, computer - based work monitoring and measurement systems: A conceptual overview. ApplErgon. 1992;23(1):6-16, http://dx.doi.org/10.1016/00036870(92)90005-G.

31. Haufler AJ, Feuerstein M, Huang GD. Job stress, upper extremity pain and functional limitations in symptomatic computer users. Am J Ind Med. 2000;38:507-15, http:// dx.doi.org/10.1002/1097-0274(200011)38:5<507::AIDAJIM3 >3.3.CO;2-X.

This work is available in Open Access model and licensed under a Creative Commons Attribution-NonCommercial 3.0 Poland License - http://creativecommons.org/ licenses/by-nc/3.0/pl/deed.en. 